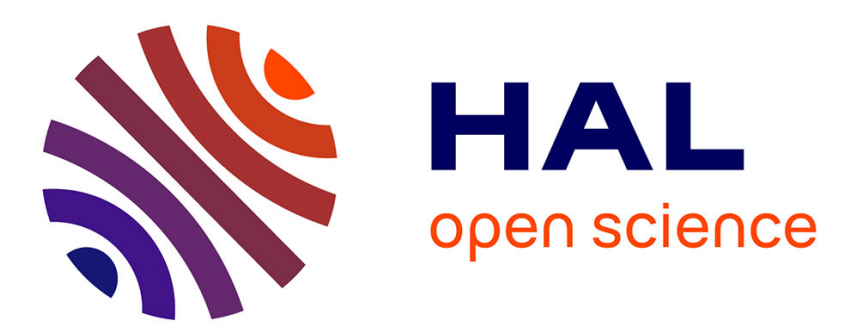

\title{
A podocyte view of membranous nephropathy: from Heymann nephritis to the childhood human disease
}

\author{
Pierre Ronco, Hanna Debiec
}

\section{To cite this version:}

Pierre Ronco, Hanna Debiec. A podocyte view of membranous nephropathy: from Heymann nephritis to the childhood human disease. Pflügers Archiv European Journal of Physiology, 2017, pp.1-9. 10.1007/s00424-017-2007-x . hal-01543682

\section{HAL Id: hal-01543682 \\ https://hal.sorbonne-universite.fr/hal-01543682}

Submitted on 21 Jun 2017

HAL is a multi-disciplinary open access archive for the deposit and dissemination of scientific research documents, whether they are published or not. The documents may come from teaching and research institutions in France or abroad, or from public or private research centers.
L'archive ouverte pluridisciplinaire HAL, est destinée au dépôt et à la diffusion de documents scientifiques de niveau recherche, publiés ou non, émanant des établissements d'enseignement et de recherche français ou étrangers, des laboratoires publics ou privés. 
This article is published as part of the Special Issue on [Functional anatomy of the kidney in health and disease]

\title{
A podocyte view of membranous nephropathy:
}

\section{From Heymann nephritis to the childhood human disease}

\author{
Pierre Ronco $^{1,2,3}$, Hanna Debiec ${ }^{1,2}$
}

${ }^{1}$ Inserm UMR_S 1155

${ }^{2}$ Sorbonne Universités, UPMC Univ Paris 06, F-75005, Paris, France

${ }^{3}$ AP-HP, Hôpital Tenon, Service de Néphrologie et Dialyses, Paris France

Short title: $M N$ and the podocyte

Address for correspondence:

Pierre Ronco, Inserm Unit 1155,

Hôpital Tenon,

4 rue de la Chine, 75020 Paris, France

tel : 33156016639

fax : 33156016999

email : pierreronco@yahoo.fr

ORCID : 0000-0002-0280-6900

Word count text: 3917 (this is without references)

Word count abstract: 188 


\section{SUMMARY}

Membranous nephropathy ( $\mathrm{MN}$ ) is characterized by an accumulation of immune deposits on the subepithelial side of the glomerular basement membrane, which results in complement activation and proteinuria. Since 2002, several major antigens of the podocyte have been identified in human $\mathrm{MN}$, the first one being neutral endopeptidase (NEP), the alloantigen involved in neonatal cases of MN that occur in newborns from NEP-deficient mothers. This discovery opened the field to the major advances that have occurred since then in the pathophysiology and treatment of MN. It is remarkable that experimental models such as Heymann nephritis and cationic bovine serum albumin-induced $\mathrm{MN}$ in the rabbit predicted the pathomechanisms of the human glomerulopathy. The podocyte is at the center of the pathogenesis of MN either by providing a source of endogenous antigens or by creating an environment favorable to deposition and accumulation of immune complexes containing exogenous (non-podocyte) antigens. The podocyte is also a victim of complement activation and antibody blocking activity against enzymes or receptors. A search for innovative drugs aimed at protecting this cell against complement activation and the effects of prolonged ER stress, has become a priority.

Key words: membranous nephropathy $(\mathrm{MN})$, podocyte, neutral endopeptidase (NEP), cationic bovine serum albumin (cBSA), complement pathways, regulated intramembrane proteolysis (RIP) 


\section{INTRODUCTION}

Membranous nephropathy ( $\mathrm{MN}$ ) is a rare disease (annual incidence, 1/100,000), but a major cause of nephrotic syndrome in the adult [58]. It is characterized by an accumulation of immune deposits on the outer aspect of the glomerular capillary wall, by the podocyte. The immune deposits consist of IgG, mainly IgG4 and IgG1, of antigens that have long eluded identification, and of the membrane attack complex of complement C5b-9 (MAC). The formation of subepithelial immune deposits results in complement activation which is responsible for functional impairment of the glomerular capillary wall causing proteinuria. The so-called "idiopathic" (or primary) MN, without any identified etiology, is an autoimmune disease involving podocyte antigens, while secondary forms involve exogenous antigens such as viral and tumoral antigens.

Advances in medical science often proceed by steps which are highly interdependent. New, groundbreaking findings with important clinical implications often result from the combination of faithful experimental models and careful clinical observations. This is well illustrated by the story of $\mathrm{MN}$ which started more than 50 years ago. It is remarkable that in this disease, experimental models predicted the pathophysiology of the human glomerulopathy. In the past 15 years, great progress has been made in the understanding of the molecular pathomechanisms of human MN. These advances were inspired by studies of experimental models of MN, such as Heymann nephritis $[15,30,71]$ and $\mathrm{MN}$ induced by cationic bovine serum albumin (BSA) in the rabbit [1, 11]. Studies of Heymann nephritis led to the concept that a podocyte antigen, megalin, could serve as a target of circulating antibodies leading to the in situ formation of immune complexes [35, 36], which put the podocyte at the center of disease mechanisms. On the other hand, cationic BSArelated MN first illustrated the case of 'planted' antigen [23]. In humans, progress in this area started in 2002 with the identification of neutral endopeptidase (NEP; also known as neprilysin) as the responsible antigen in a rare subset of patients with alloimmune neonatal MN [21, 22]. This finding provided the proof of concept that a podocyte antigen could be responsible for human MN, as is the case for megalin in the rat, and laid the foundation for the identification of the M-type receptor for secretory phospholipase $\mathrm{A}_{2}\left(\mathrm{PLA}_{2} \mathrm{R} 1\right)$, which was the first podocyte autoantigen shown to be involved in idiopathic $\mathrm{MN}$ in humans, soon followed by thrombospondin domain-1 containing 7A $[8,68]$. Non-podocyte circulating antigens can also be involved as is the case in children for cationic bovine serum albumin (BSA) or enzymes used in enzyme replacement therapy for lysosomal storage disorders, [23] who represent the human counterpart to the rabbit model of 
"planted" antigen first described by Border et al in the early 1980's [11]. In these diseases also, the podocyte is an actor because of defective clearance properties.

This review will focus on the role of the podocyte, both as a culprit and a victim. in Heymann nephritis, NEP-related neonatal MN, and other childhood MN.

\section{HEYMANN NEPHRITIS: THE PODOCYTE AS A TARGET OF ANTI-MEGALIN ANTIBODIES}

In 1959, Heymann et al [30] described a rat model of MN, referred to as active Heymann nephritis, which was induced by the immunization of Lewis rats with crude kidney extracts and was reminiscent of the disease in humans. Because the subepithelial deposits were induced by fractions of renal brush-border membrane from the proximal tubule rather than by glomerular extracts, the deposits were initially believed to result from the glomerular trapping of circulating immune complexes composed of brush-border-related antigens and the corresponding antibodies. Subsequently, however, the development of passive Heymann nephritis in rats injected with rabbit anti-rat brush-border antibodies argued against a role for circulating immune complexes $[15,71]$. In the passive Heymann nephritis model, immune deposits occur within minutes of antibody injection, which argues against formation of immune compexes in the circulation followed by their deposition in the glomerular capillary wall. By using ex vivo and isolated perfused kidney systems, Van Damme et al [71] and Couser et al [15] demonstrated that anti-brush-border antibodies bound to an antigenic target located on podocytes, which indicated that the disease was caused by the in situ formation of immune complexes.

The principal autoantigen in both active and passive Heymann nephritis was identified in the early 1980s $[35,36]$. This autoantigen is a large podocyte transmembrane protein called megalin (also known as LDL receptor-related protein 2), with a molecular weight of $\sim 600 \mathrm{kDa}[60,75]$. This polyspecific receptor, which belongs to the LDL receptor superfamily, is present at the sole of podocyte foot processes in clathrin-coated pits. The formation of immune deposits is fueled by the de novo synthesis of megalin [2]. Epitope mapping showed that although subepithelial immune deposits could be induced by all four megalin ligand-binding domains [55, 60, 75], full-blown disease with proteinuria was associated with a specific epitope located in the first ligand-binding domain of megalin, in a $60 \mathrm{kDa}$ N-terminal fragment $[54,69,70]$, and with diffusion of immune response to other megalin epitopes, a process named intramolecular epitope spreading [64]. 
Heymann nephritis-like MN was also reported in rats and mice[4-6, 59], in which the target antigen was dipeptidyl peptidase 4. More recently, a model of passive Heymann nephritis was induced in mice injected with antipodocyte serum [46, 47]. Although studies of Heymann nephritis have greatly contributed to our understanding of the pathomechanisms of $\mathrm{MN}$ (see below), there is no evidence that megalin is involved in human $\mathrm{MN}$.

\section{THE PODOCYTE NEUTRAL ENDOPEPTIDASE AND ALLOIMMUNE MN}

This rare form of $\mathrm{MN}$ was first identified in a neonate borne with respiratory distress and acute renal failure followed by nephrotic range proteinuria and hypertension [22]. Because of early occurrence of the disease in the last trimester of pregnancy, we hypothesized that the mother became immunized during pregnancy and the pathogenic antibodies were transferred to the fetus (Figure 1). Involvement of NEP antigen was suspected because of interspecies differences in reactivity observed when human, rat and rabbit kidneys were incubated with sera from the mother and her infant. Identification of NEP was confirmed by immunoprecipitation of rat brush-border extracts $[21,22]$. Transfer experiments, in which a pregnant rabbit was injected with the mother's IgG fraction, and colocalization of NEP, IgG and C5-b9 within the subepithelial immune deposits, established that the disease was caused by anti-NEP antibodies [21, 57]. NEP not only is an antigen, it also is an enzyme involved in the degradation of biologically active peptides such as enkephalin (for this reason, it is also called enkephalinase), natriuretic peptides, endothelin, bradykinin and substance $\mathrm{P}$ in the vicinity of their receptors. In the kidney, NEP is present at the podocyte surface, in the brush border of the proximal tubule and in vessel walls. It is found in numerous organs but in very specific localizations, and in granulocytes as well. NEP is identical to the common acute lymphoblastic leukaemia antigen (CALLA) and to CD10.

Because the mother did not show any renal manifestation even though she had persistently high titers of anti-NEP antibody, we hypothesized that she might be deficient in NEP. This hypothesis was supported by the lack of reactivity of her granulocyte extracts with a panel of antiNEP antibodies [21]. Four additional families with materno-fetal alloimmune MN were identified. All immunized mothers were NEP deficient as a result of the same truncating mutation in exon 7 of the NEP gene $[22,73]$, (Figure 1). In the first family, the mother was a compound heterozygote for this mutation and for another truncating mutation in exon 15. A founder effect by a common ancestor is suspected because the same mutation in exon 7 was identified in all families. 
Alloimmunization can be triggered by previous spontaneous miscarriages or by the ongoing pregnancy during which the mother's immune system is first exposed to the NEP of paternal origin on syncytiotrophoblastic cells. The NEP-deficient individuals had normal blood pressure, renal functional tests, and lymphocyte phenotype and function [22], whereas NEP null mice showed hypotension, greater sensitivity to septic shock, early onset Alzheimer's disease and prostatic tumors [45]. Because mutations in the NEP gene are asymptomatic, one can expect a high prevalence in selected populations.

After birth, renal failure and the nephrotic syndrome rapidly improved in all children in parallel with the disappearance from the child's blood of maternal IgG. However, a newborn had persisting renal failure requiring dialysis despite exchange transfusions. This case led to conclude that the anti-NEP IgG1 was responsible for the disease because the mother had high titers of anti-NEP IgG1 with very low titer of anti-NEP IgG4 and other IgG subclasses. This finding is in keeping with the capacity of IgG1 to activate complement whereas IgG4 usually fail to do so. Another patient with the longest follow-up, developed severe chronic renal failure with nephrotic range proteinuria leading to end-stage renal disease requiring transplantation. Although a repeat kidney biopsy could not be performed, the delayed renal manifestations might be induced by advanced MN combined with the postponed consequences of immunologically mediated antenatal nephron loss. Antibodies against idiotypes or allotypes on the maternal $\mathrm{IgG}$ might also have contributed to further progression of the disease. These observations suggest that cases of $\mathrm{MN}$ or chronic renal failure diagnosed during adolescence or early adulthood might be the late consequence of anti-NEPinduced antenatal renal disease.

Fetomaternal alloimmune glomerulopathy defines a novel organ-specific, fetomaternal disease because of alloimmunization induced by a genetic defect in the mother which leads to the development of $\mathrm{MN}$ in her fetus. Rhesus incompatibility was as yet the paradigm of fetomaternal diseases resulting from alloimmunization, which were long considered to be restricted to red blood cells and platelets. Our findings suggest that truncating mutations in genes coding for other podocyte antigens, asymptomatic for the carrier mother, could induce alloimmune glomerulopathy in the neonate. They open new perspectives for neonatal diseases affecting other organs than the kidney. 


\section{NON-PODOCYTE ANTIGENS IN CHILDHOOD MN}

Altough not being a source of exogenous antigens (per definition), the podocyte also plays a role in MN caused by exogenous antigens which become planted in the glomerular capillary wall because it creates a favorable situation to the growth of immune complexes either by contributing to the synthesis of basement components and cell surface molecules with a negative charge (interacting with positively charged exogenous molecules coming from the blood) or because of its defective clearance properties. These 2 situations are illustrated by BSA-related $\mathrm{MN}$ and enzyme replacement therapy (ERT)-caused MN, respectively (Figure 2).

\section{Bovine serum albumin and other dietary antigens}

$\mathrm{MN}$ is one of the most common causes of nephrotic syndrome in adults but this disease is rarely diagnosed in paediatric populations $[7,13]$. We have identified BSA as a novel antigen in children with $\mathrm{MN}$ aged $<5$ years [23]. These cases that can be considered as the human counterpart to the experimental model in rats and mice induced by cationized BSA [11, 14, 41], open up new perspectives as to a role of dietary and environmental factors in $\mathrm{MN}$, and more generally in glomerular diseases.

In this model of $\mathrm{MN}$, podocyte antigens do not contribute to the formation of immune deposits which involve an exogenous antigen, BSA, that becomes implanted in the glomerular capillary wall (see Beck et al in this issue). The antigen charge is a key factor for disease induction. Only the animals that were intravenously given chemically modified cationized BSA shortly after immunization with this antigen developed $\mathrm{MN}[11,14,41]$. When native, slightly acidic BSA was injected, animals did not develop the disease. Positively charged cationic BSA bound to the anionic glomerular capillary wall because of electrostatic interactions instead of being taken up by endocytosis in podocytes, and could then serve as a target for circulating antibodies.

We speculated that the same pathophysiological scenario might occur in humans. High levels of circulating anti-BSA antibodies of IgG1 and IgG4 subclasses were identified in children and adults with MN whereas anti-BSA IgE was not detected. Circulating BSA antigen was identified in the patients with the higher levels of anti-BSA antibodies. BSA immunopurified from children' sera migrated in the basic range of $\mathrm{pH}$ whereas in adult patients, it migrated in the neutral region as native BSA. BSA antigen was co-localized with $\mathrm{IgG}$ in subepithelial immune deposits only in the children with both circulating cationic BSA and anti-BSA antibodies, but in none of the adult 
patients with MN, which strongly supported the assumption that both cationic BSA serving as a "planted antigen" and concomitant immunization against this antigen could induce MN. Additionally, decrease of cationic BSA and antibody levels during MN remission reinforced a direct causal link with the disease. Contrary to the observation made in the majority of adults with MN, neither PLA2R autoantibodies nor PLA2R antigen were detected in the blood and subepithelial immune deposits, respectively, in the children with BSA-related MN [23].

Cow's milk is the major source of BSA in young children. However, the origin of cationic BSA remains obscure. In modern dietary culture, food ingredients are subjected to a variety of processing conditions and contain many additives. Some of these technological processes might induce alterations of food proteins, which could in turn change their physicochemical properties and digestion in the gastrointestinal tract $[20,61,62]$. On the other hand, it is conceivable that intestinal microbiota and frequent episodes of gastroenteritis as commonly observed in children might lead to pathological modifications of BSA [66].

Although very soluble in water and rich in amino-acids recognized by gastrointestinal enzymes, BSA is relatively resistant to digestion. Heat treatment of BSA induces denaturation of the protein and results in reduced proteolysis [3]. at the relatively high $\mathrm{pH}$ (3-4) of the infants' stomach compared with that of adults ( $\mathrm{pH} 2)$ [63] In addition, the amount of intact BSA that enters the intestinal circulation is likely higher during infancy before the gastrointestinal tract has matured and its barrier function has been established $[66,72]$. Finally, modification of BSA could directly affect how this protein is cleaved and processed in vivo. Both the predominance of a cationic form and the increased amount of absorbed BSA most likely contribute to the development of $\mathrm{MN}$ in young children.

\section{Enzyme replacement therapy as a cause of alloimmune MN}

Alloimmune reactions can occur during enzyme replacement therapy $[12,40,56]$. Because of the absence or very low levels of enzyme in many patients, therapeutic proteins are potential alloantigens that commonly trigger immunization. Allo-antibodies may be without clinical significance or may lead to hypersensitivity reactions, decreased bioavailability, and reduced efficacy of the therapeutic proteins. Only two cases of MN have been reported so far, but the prevalence of ERTinduced renal complications is probably underestimated.

A first case of nephrotic syndrome with mesangial and subepithelial Ig deposits was reported in a highly sensitized patient with Pompe disease treated with recombinant human alpha- 
glucosidase (rhGAA) [32]. The second case was a patient with mucopolysaccharidosis type VI treated with recommended doses of human recombinant arylsulfatase B (rhASB) who developed typical MN [24]. It is remarkable that this patient developed a nephrotic syndrome of rapid onset just one week after surgery although prior, regular screens for proteinuria were negative . Titers of anti-rhSAB antibody were high but in the same range as in other patients receiving rhASB without renal complication [28, 29]. It is likely that drugs given during the perioperative period had deleterious effects on podocyte physiological properties. The patient received a cocktail of anesthetic drugs, which were before shown to increase glomerular permeability to proteins and alter podocyte function [27]. Further, the patient was anesthetized with sevoflurane, which can affect the conductance of $\mathrm{Ca}^{2+}$-activated $\mathrm{K}^{+}$channel expressed on podocytes $[49,51]$.

These cases thus add a new cause to the list of $\mathrm{MN}$ aetiologies. They point to careful monitoring of proteinuria in all patients receiving ERT. Considering the critical requirement for ERT in patients with lysosomal enzyme deficiencies, it should be stressed that intensive immunosuppressive therapy can allow reintroduction of ERT resulting in a dramatic improvement of the patient's condition without relapse of the renal disease.

\section{MECHANISMS OF PODOCYTE INJURY}

In this chapter, we will focus on Heymann nephritis and childhood MN (Figure 2). The reader will find further information on PLA2R- and THSD7A in another chapter devoted to adult MN.

\section{Mechanisms of immune complex formation}

Megalin, a member of the LDL-receptor superfamily, is concentrated in clathrin-coated pits. Epitope-specific IgG arrives from the circulation to form immune complexes with megalin on the podocyte membrane, followed by shedding and rapid immobilization in the glomerular basement membrane, thus preventing clearing of complexes by endocytosis of the podocyte. Large immune deposits form by repeated cycles of this mechanism [37]. Although megalin is clearly involved in the formation of immune deposits, one does not know whether the complete form of megalin or a proteolytic form is deposited extracellurly.

In the proximal tubule where megalin is strongly expressed, Biemersderfer's laboratory [9] have shown that megalin is subjected to regulated intramembrane proteolysis (RIP), an 
evolutionarily conserved process linking receptor function with transcriptional regulation. Best characterized by the Notch signaling pathway, RIP involves regulated ectodomain shedding followed by $\gamma$-secretase-mediated release of the C-terminal, cytosolic domain. The C-terminus in turn translocates to the nucleus where it interacts with other proteins to regulate expression of specific genes. Megalin is subjected to protein kinase C-regulated, metalloprotease-mediated ectodomain shedding producing a membrane-associated C-terminal fragment (MCTF). The MCTF in turn forms the substrate for $\gamma$-secretase. These data implicate megalin as a central element of a Notch-like signaling pathway linking protein reabsorption and gene regulation in proximal tubule. Megalin processing potentially triggered by anti-megalin antibodies, may also play an important role in podocyte alterations in Heymann nephritis.

Of note, PLA2R1 and THSD7A, the 2 major antigens in primary MN in the adult, are also subjected to proteolytic cleavage, and their involvement in RIP deserves further investigations.

\section{Complement-mediated injury}

Complement activation and formation of the C5b-9 attack complex, which is triggered by immune complex deposition, have major roles in sublethal podocyte injury and proteinuria $[16,19,53]$, (Figure 2). C5b-9, in sublytic quantities that do not kill podocytes, activates various mediators, such as phospholipases, protein kinases, cyclooxygenases, transcription factors and cytokines. These signals influence podocyte cell metabolic pathways, structure and function of key cytoskeletal proteins, expression and localization of nephrin, the turnover of extracellular matrix, and DNA integrity $[16,19,53]$. Evidence also shows that assembly of the sublytic C5b-9 complex on podocytes causes upregulation of NADPH oxidoreductase expression and its translocation to the cell surface. Subsequently, reactive oxygen species are produced locally, which leads to damage of podocyte lipids, membrane proteins and glomerular basement membrane components [16, 19, 33, 53]. The injured podocytes also produce new extracellular matrix that is assembled between and around the immune deposits giving rise to the characteristic "spikes" that are well visualized by silver staining. Genetic polymorphisms resulting in reduced activity of circulating or podocyte complement regulatory proteins (CRP) as well as intrinsic or acquired defect of these proteins which control the alternative pathway of complement activation, could contribute as well to pathogenesis of $\mathrm{MN}$ and account for its varying severity. 


\section{Direct effector role of antibodies}

Despite numerous studies supporting a role for complement in the pathogenesis of experimental $\mathrm{MN}$, proteinuria and podocyte damage may also occur without assembly of C5b-9 [43, 65]. In addition to forming immune complexes, anti-podocyte antibodies may directly alter podocyte biology. Both megalin and PLA ${ }_{2} \mathrm{R}$ are cell surface receptors, and NEP cleaves biologically active peptides at the cell surface. Anti-megalin antibodies were shown to inhibit the uptake of lipoproteins that normally bind the multiligand receptor megalin [34]. The accumulation of lipoproteins (apoE and apoB) within the immune deposits together with the production of reactive oxygen species (ROS) potentially favors the formation of lipid peroxidation products.

The dual effect of pathogenic antibodies is well illustrated by anti-NEP antibodies. Mothers producing anti-NEP IgG1 transmitted the disease whereas those producing anti-NEP IgG4 only, failed to do so. These findings point to a critical role of the classical pathway of complement activation as attested by C1q deposition, whereas in adult cases of PLA2R-related autoimmune nephropathy anti-PLA2R IgG4 is prevailing and C1q deposits are rare. On the other hand, NEP also has important enzymatic in the kidney where it is present at the podocyte surface, in the brush border of the proximal tubule, and in vessel walls [25]. NEP-specific IgG1 had a strong inhibitory effect, whereas IgG4 had a very weak effect. Inhibition of NEP activity by anti-NEP IgG1 antibodies may alter metabolism of a number of regulatory peptides and thus have an impact on glomerular hemodynamics, endothelial permeability, tubular function, and podocyte lesions [26, 31, $44,45]$. These alterations may be the cause of the unusual, severe ischemic lesions observed in the biopsy and of the disappearance of NEP from the brush border of proximal tubules, as also noted in ischemic and toxic acute kidney injuries [42, 52].

It is likely that antibodies directed against PLA2R and THSD7A also behave as bifunctional antibodies activating complement and blocking protein/receptor function, which must be taken into account in the interpretation of the mechanisms of the nephrotic syndrome and of podocytopenia, a major feature of adult $\mathrm{MN}$.

\section{Podocyte recovery and protective mechanisms}

In parallel with the various cell damaging signals triggered by C5b-9, other signals are activated to limit complement-induced injury and to promote recovery (Figure 2). Nucleated cells are equipped with several mechanisms that support resistance to complement-dependent cytotoxicity [10, 16, 67]. One of the most important protective mechanisms is endocytosis and ectocytosis of the C5b-9. In 
disease state, C5b-9 inserted into the podocyte membrane is transported intracellularly and extruded into the urinary space, where it is considered as a dynamic marker of ongoing immunologic injury $[38,50]$. In injured podocytes, an accumulation of misfolded proteins in the endoplasmic reticulum (ER) leads to ER stress [17, 39]. Various studies in animal models and human diseases imply that complement may upregulate the adaptive unfolded protein response together with the ubiquitinproteasome system and autophagy [18, 48, 74]. This response is one of the most potent cytoprotective mechanisms against accumulation of misfolded proteins inside podocytes. However, sustained ER stress may be cytotoxic by causing activation of pro-apoptotic pathways leading to destruction of podocytes [48]. Mechanisms of immune-mediated podocyte injury, disease progression, and recovery are summarized in Fig. 1

\section{PERSPECTIVES}

Because the etiology and pathogenesis of MN involve the interplay of a variety of factors acting at different stages of the disease, optimum therapy should be multifaceted being directed at multiple targets and adapted with time (Figure 2). For example at initial stages, a combination of approaches including blocking antibody production, inhibiting complement activation at the site of complement activity, and protecting podocyte from injury triggered by complement activation and C5b-9 assembly should be considered. One major pitfall in $\mathrm{MN}$ is the lack of reliable biomarkers with diagnostic, prognostic, and therapeutic values. In addition to the now classical antibodies, the clinical complexity of the disease suggests that a combination of prognostic markers would be the best option for prediction of clinical outcome, recurrence on the graft, and personalized therapy

In conclusion, the podocyte is at the center of the pathogenesis of MN either by providing a source of endogenous antigens or by creating an environment favorable to deposition and accumulation of immune complexes containing exogenous (non-podocyte) antigens. The podocyte is also a victim of complement activation and antibody blocking activity against enzymes or receptors. For these reasons, the podocyte should be targeted by innovative drugs aimed at protecting this cell against complement activation and the effects of prolonged ER stress. One should keep in mind that despite successful immunosuppressive treatment, decrease of proteinuria often lags much behind immunological remission, most likely because of irreversible alterations of podocytes. 


\section{Acknowledgments}

The research of the authors is supported by grants from European Research Council (ERC2012-ADG_20120314; Grant Agreement $n^{\circ}$ 322947), and the 7th Framework Programme of the European Community, contract 2012-305608 «European Consortium for High-Throughput Research in Rare Kidney Diseases (EURenOmics) »

\section{References}

1. Adler SG, et al (1983) Electrical charge. Its role in the pathogenesis and prevention of experimental membranous nephropathy in the rabbit. J Clin Invest $71: 487-499$.

2. Allegri L, et al (1986) Polyvalent antigen-antibody interactions are required for the formation of electron-dense immune deposits in passive Heymann's nephritis. Am J Pathol 125: 1-6.

3. Alting AC, Meijer RJ, van Beresteijn EC (1997) Incomplete elimination of the ABBOS epitope of bovine serum albumin under simulated gastrointestinal conditions of infants. Diabetes Care 20:875-880.

4. Assmann KJ, et al (1983) Membranous glomerulonephritis in the mouse. Kidney Int 24:303312.

5. Assmann KJ, et al (1985) Comparison of antigenic targets involved in antibody-mediated membranous glomerulonephritis in the mouse and rat. Am J Pathol 121: 112-122.

6. Assmann KJ, et al (1989) Involvement of an antigen distinct from the Heymann antigen in membranous glomerulonephritis in the mouse. Lab Invest 60: 138-146.

7. Avner ED, Harmon WE, Niaudet P (2004) Pediatric Nephrology $5^{\text {th }}$ edition : pp 643-45.

8. Beck LH Jr, et al (2009) M-type phospholipase A2 receptor as target antigen in idiopathic MN. N Engl J Med 361: 11-21.

9. Biemesderfer D (2006) Regulated intramembrane proteolysis of megalin: linking urinary protein and gene regulation in proximal tubule? Kidney Int 69:1717-1721.

10. Bohana-Kashtan O, Ziporen L, Donin N, et al (2004) Cell signals transduced by complement. Mol Immunol 41:583-597.

11. Border WA, et al (1982) Induction of membranous nephropathy in rabbits by administration of an exogenous cationic antigen. J Clin Invest 69: 451-461.

12. Brooks DA (1999) Immune response to enzyme replacement therapy in lysosomal storage disorder patients and animal models. Mol Genet Metab 68:268-275.

13. Chen A, Frank R, Vento S, et al (2007) Idiopathic membranous nephropathy in pediatric patients: presentation, response to therapy, and long-term outcome. BMC Nephrol 6:8-11. 
14. Chen JS, Chen A, Chang LC, et al (2004) Mouse model of membranous nephropathy induced by cationic bovine serum albumin: antigen dose-response relations and strain differences. Nephrol Dial Transplant 19: 2721-2728.

15. Couser WG, et al (1978) Experimental glomerulonephritis in the isolated perfused rat kidney. J Clin Invest 62: 1275-1287.

16. Cunningham PN, Quigg RJ (2005) Contrasting roles of complement activation and its regulation in membranous nephropathy. J Am Soc Nephrol 16: 1214-1222.

17. Cybulsky AV (2010) Endoplasmic reticulum stress in proteinuric kidney disease. Kidney Int 7:187-193.

18. Cybulsky AV (2013) The intersecting roles of endoplasmic reticulum stress, ubiquitinproteasome system, and autophagy in the pathogenesis of proteinuric kidney disease. Kidney Int 84:25-33.

19. Cybulsky AV, Quigg RJ, Salant DJ (2005) Experimental membranous nephropathy redux. Am J Physiol Renal Physiol 289: F660-F671.

20. Davis PJ, Williams SC (1998) Protein modification by thermal processing. Allergy 53:102105.

21. Debiec H, et al (2002) Antenatal membranous glomerulonephritis due to anti-neutral endopeptidase antibodies. N Engl J Med 346: 2053-2060.

22. Debiec H, et al (2004) Role of Truncating mutations in MME gene in feto-maternal alloimmunization and neonatal glomerulopathies. Lancet 364: 1252-1259.

23. Debiec H, Lefeu F, Kemper MJ, et al (2011) Early-childhood membranous nephropathy due to cationic bovine serumalbumin. N Engl J Med 364:2101-2110.

24. Debiec H, Valayannopoulos V, Boyer O, et al (2014) Allo-immune membranous nephropathy and recombinant aryl sulfatase replacement therapy: A need for tolerance induction therapy. J Am Soc Nephrol 25:675-680.

25. Dussaule JC, Stefanski A, Bea ML et al. (1993) Characterization of neutral endopeptidase in vascular smooth muscle cells of rabbit renal cortex. Am J Physiol 264 : F45-F52.

26. Friedrich C, Endlich N, Kriz W et al. (2006) Podocytes are sensitive to fluid shear stress in vitro. Am J Physiol Renal Physiol291: F856-F865.

27. Giardino L, et al (2009) Podocyte glutamatergic signaling contributes to the function of the glomerular filtration barrier. J Am Soc Nephrol 20: 1929-1940.

28. Harmatz P, Giugliani R, Schwartz I, et al (2006) Enzyme replacement therapy for mucopolysaccharidosis VI: A phase 3, randomized, double-blind, placebo-controlled, multinational study of recombinant human $\mathrm{N}$-acetylgalactosamine 4-sulfatase (recombinant human arylsulfatase B or rhASB) and follow-on, open-label extension study. J Pediatr 148: 533-539. 
29. Hendriksz CJ, Giugliani R, Harmatz P, et al (2013) Design, baseline characteristics, and early findings of the MPS VI (mucopolysaccharidosis VI) Clinical Surveillance Program (CSP). J Inherit Metab Dis 36: 373-384.

30. Heymann W, et al (1959) Production of nephrotic syndrome in rats by Freund's adjuvants and rat kidney suspension. Proc Soc Exp Biol Med 100:660-664.

31. Hu P, Xuan Q, Hu B et al.(2013) Anti-neutral endopeptidase, natriuretic peptides disarrangement, and proteinuria onset in membranous nephropathy. Mol Biol Rep 40 : 2963-2967.

32. Hunley TE, Corzo D, Dudek M, et al (2004) Nephrotic syndrome complicating alphaglucosidase replacement therapy for Pompe disease. Pediatrics 114:e532-535.

33. Kerjaschki D (2000) Pathogenetic concepts of membranous glomerulopathy (MGN). J Nephrol 13: S96-S100.

34. Kerjaschki D, Exner M, Ullrich R, et al (1997) Pathogenic antibodies inhibit the binding of apolipoproteins to megalin/gp330 in passive Heymann nephritis. J Clin Invest 100: 23032309.

35. Kerjaschki D, Farquhar MG (1982). The pathogenic antigen of Heymann nephritis is a membrane glycoprotein of the renal proximal tubule brush border. Proc Natl Acad Sci 79:5557-5561.

36. Kerjaschki D, Farquhar MG (1983) Immunocytochemical localization of the Heymann nephritis antigen (gp330) in glomerular epithelial cells of normal Lewis rats. J Exp Med 157: 667-686.

37. Kerjaschki D, Miettinen A, Farquhar MG (1987) Initial events in the formation of immune deposits in passive Heymann nephritis. gp330-anti-gp330 immune complexes form in epithelial coated pits and rapidly become attached to the glomerular basement membrane. $\mathrm{J}$ Exp Med 166:109-128.

38. Kerjaschki D, Schulze M, Binder S, et al (1989) Transcellular transport and membrane insertion of the C5b-9 membrane attack complex of complement by glomerular epithelial cells in experimental membranous nephropathy. J Immunol 143:546-552

39. Kon SP, Coupes B, Short CD, et al (1995) Urinary C5b-9 excretion and clinical course in idiopathic human membranous nephropathy. Kidney Int 48:1953-1958.

40. Koren E, Zuckerman LA, Mire-Sluis AR (2002) Immune responses to therapeutic proteins in humans--clinical significance, assessment and prediction. Curr Pharm Biotechnol 3:349360 .

41. Koyama A, Inage H, Kobayashi M, et al (1986) Effect of chemical cationization of antigen on glomerular localization of immune complexes in active models of serum sickness nephritis in rabbits. Immunology 58: 529-534.

42. Lebeau C, Debelle FD, Arlt VM et al.(2005) Early proximal tubule injury in experimental aristolochic acid nephropathy: functional and histological studies. Nephrol Dial Transplant 20: $2321-2332$. 
43. Leenaerts PL, Hall BM, Van Damme BJ, et al (1995) Active Heymann nephritis in complement component C6 deficient rats. Kidney Int 47: 1604-1614.

44. Lewko B, Goos M, Latawiec E et al. (2006) Regulation of cGMP synthesis in cultured podocytes by vasoactive hormones. J Physiol Pharmacol 57: 599-610.

45. Lu B, Figini M, Emanueli C et al. (1997) The control of microvascular per- meability and blood pressure by neutral endopeptidase. Nat Med 3: 904-907.

46. Meyer TN, et al (2007) A new mouse model of immune-mediated podocyte injury. Kidney Int 72: 841-852.

47. Meyer-Schwesinger C, et al (2011) Nephrotic syndrome and subepithelial deposits in a mouse model of immune-mediated anti-podocyte glomerulonephritis. J Immunol 187: 32183229 .

48. Meyer-Schwesinger C, Meyer TN, Münster S, et al (2009) A new role for the neuronal ubiquitin C-terminal hydrolase-L1 (UCH-L1) in podocyte process formation and podocyte injury in human glomerulopathies. J Pathol 217:452-464.

49. Morton MJ, et al (2004) Human podocytes possess a stretch-sensitive, Ca2+-activated K+ channel: Potential implications for the control of glomerular filtration. J Am Soc Nephrol 15: 2981-2987.

50. Moskovich O, Fishelson Z (2000) Live cell imaging of outward and inward vesiculation induced by the complement c5b-9 complex. J Biol Chem 28:29977-29986.

51. Namba $\mathrm{T}$, et al (2000) Inhibition of the human intermediate conductance $\mathrm{Ca}(2+)$-activated $\mathrm{K}(+)$ channel, hIK1, by volatile anesthetics. Eur J Pharmacol 395: 95-101.

52. Nambi P, Pullen M, Wu HL et al. (1999) Down regulation of kidney neutral endopeptidase mRNA, protein and activity during acute renal failure:possible mechanism for ischemiainduced acute renal failure in rats? Mol Cell Biochem 197: 53-59.

53. Nangaku M, Shankland SJ, Couser WG (2005) Cellular response to injury in membranous nephropathy. J Am Soc Nephrol 16;1195-1204.

54. Oleinikov AV, Feliz BJ, Makker SP (2000) A small N-terminal 60-kD fragment of gp600 (megalin), the major autoantigen of active Heymann nephritis, can induce a full-blown disease. J Am Soc Nephrol 11: 57-64.

55. Raychowdhury R, et al (1996) Induction of Heymann nephritis with a gp330/megalin fusion protein. Am J Pathol 148: 1613-1623.

56. Richards SM (2002) Immunologic considerations for enzyme replacement therapy in the treatment of lysosomal storage disorders. Clin Appl Immunol Rev 2:241-253.

57. Ronco P, Debiec H (2005) Molecular pathomechanisms of membranous nephropathy: from Heymann nephritis to alloimmunization. J Am Soc Nephrol 16: 1205-1213.

58. Ronco P, Debiec H (2015) Pathophysiological advances in membranous nephropathy: time for a shift in patient's care. Lancet 385:1983-1992. 
59. Ronco P, et al (1984) A monoclonal antibody to brush border and passive Heymann nephritis. Clin Exp Immunol 55: 319-332.

60. Saito A, et al (1996) Mapping rat megalin: the second cluster of ligand binding repeats contains a 46-amino acid pathogenic epitope involved in the formation of immune deposits in Heymann nephritis. Proc Natl Acad Sci U S A 93: 8601-8605.

61. Sanchez C, Fremont S (2003) Consequences of heat treatment and processing of food on the structure and allergenicity of component proteins. Rev Fr Allergol Immunol Clin 43:13-20.

62. Sathe SK, Teuber SS, Roux KH (2005) Effects of food processing on the stability of food allergens. Biotechnol Adv 23:423-429.

63. Schmidt DG, Meijer RJ, Slangen CJ, et al (1995) Raising the pH of the pepsin-catalysed hydrolysis of bovine whey proteins increases the antigenicity of the hydrolysates. Clin Exp Allergy. 25:1007-1017.

64. Shah P, Tramontano A, Makker SP (2007) Intramolecular spreading in Heymann nephritis. J Am Soc Nephrol 18: 3060-3066.

65. Spicer ST, Tran GT, Killingsworth MC, et al (2007) Induction of passive Heymann nephritis in complement component 6-deficient PVG rats. J Immunol 179: 172-178.

66. Sreedharan R, Mehta DI (2004) Gastrointestinal tract. Pediatrics 113:1044-1050.

67. Tegla CA, Cudrici C, Patel S, et al (2011) Membrane attack by complement: the assembly and biology of terminal complement complexes. Immunol Res 51:45-60.

68. Tomas NM, Beck LH Jr, Meyer-Schwesinger C, et al (2014) Thrombospondin type-1 domain-containing 7A in idiopathic membranous nephropathy. N Engl J Med 371:22772287.

69. Tramontano A, Knight T, Vizzuso D, Makker SP (2006) Nested N-terminal megalin fragments induce high-titer autoantibody and attenuated Heymann nephritis. J Am Soc Nephrol 17:1979-1985.

70. Tramontano A, Makker SP (2004) Conformation and glycosylation of a megalin fragment correlate with nephritogenicity in Heymann nephritis. J Immunol 172: 2367-2373.

71. Van Damme BJ, et al (1978) Experimental glomerulonephritis in the rat induced by antibodies directed against tubular antigens. V. Fixed glomerular antigens in the pathogenesis of heterologous immune complex glomerulonephritis. Lab Invest 38:502-510.

72. van Elburg RM ,Fetter WP, Bunkers CM, et al (2003) Intestinal permeability in relation to birth weight and gestational and postnatal age. Arch Dis Child Fetal Neonatal Ed. 88:F5255 .

73. Vivarelli M, Emma F, Pellé T, et al (2015) Genetic homogeneity but IgG subclassdependent clinical variability of alloimmune membranous nephropathy with anti-neutral endopeptidase antibodies. Kidney Int 87:602-609. 
74. Wang L, Hong Q, Lv Y, et al (2012) Autophagy can repair endoplasmic reticulum stress damage of the passive Heymann nephritis model as revealed by proteomics analysis. $\mathbf{J}$ Proteomics. 75:3866-3876.

75. Yamazaki H, et al (1998) All four putative ligand-binding domains in megalin contain pathogenic epitopes capable of inducing passive Heymann nephritis. J Am Soc Nephrol 9:1638-1644.

\section{Figure legends}

\section{Figure 1. Pathophysiological scenario of fetomaternal alloimmune glomerulopathy} (FMAIG) caused by maternal anti-NEP antibodies.

Neutral endopeptidase (NEP, blue dots) serves as pathogenic antigen in the podocyte cell membrane. Antibodies to this protein originate in women who genetically lack NEP because of truncating mutations in the $M M E$ gene coding for NEP. Immunization occurs during pregnancy when the mother's immune system is first exposed to NEP strongly expressed by placental cells and by fetal cells entering the mother's blood. From about the 18th week of gestation, maternal antibodies of the IgG class are actively transported across the placenta to the fetus, where they bind to the NEP antigen expressed on podocytes.

Figure 2. Mechanisms of immune mediated podocyte injury and disease progression in MN and pathogenesis based therapeutic approach.

The in situ formation of immune complexes is initiated by binding of circulating antibodies to antigens that are endogenous integral membrane proteins of the podocyte, or to exogenous antigens planted in the glomerular basement membrane. Complement activation and formation of the C5b-9 attack complex, which is triggered by immune complex deposition, have major roles in sublethal podocyte injury and proteinuria. In addition anti-podocyte antibodies can directly influence the function of target antigens. Distinct cytoprotective responses are observed over time in cells undergoing endoplasmic reticulum (ER) stress. Prolonged ER stress beyond threshold results in apoptosis.

Therapeutic interventions are represented at four different stages of the disease: elimination of toxics and diet compounds such as bovine serum albumin; depletion of antibodies, ideally by specific immunointervention; inhibition of complement activation and effects; and protection of 
the podocyte, particularly against the effects of prolonged endoplasmic reticulum stress, or therapeutic intervention favoring cell repair. 
Figure 1

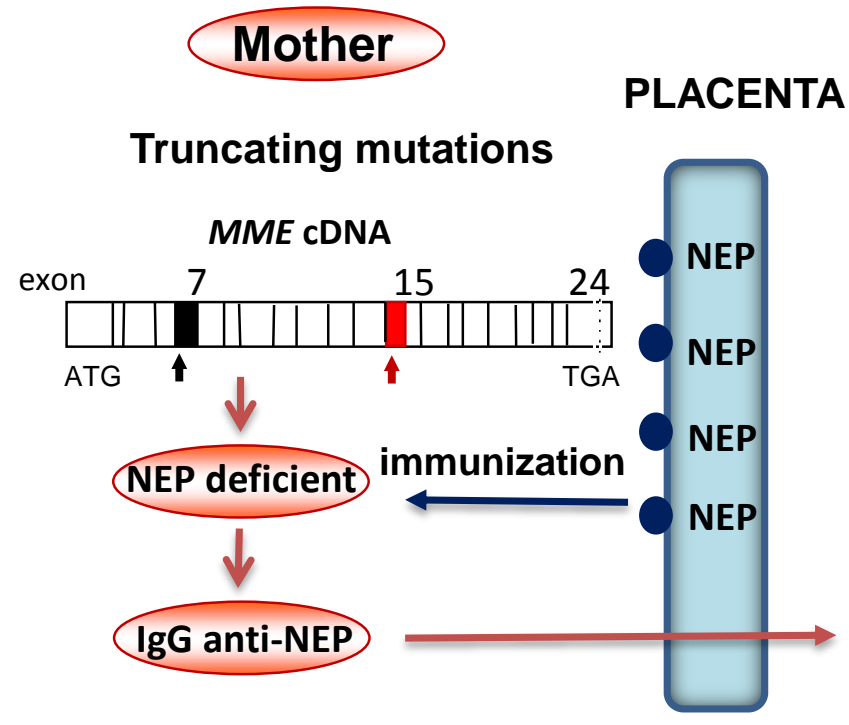

\section{Fetus}

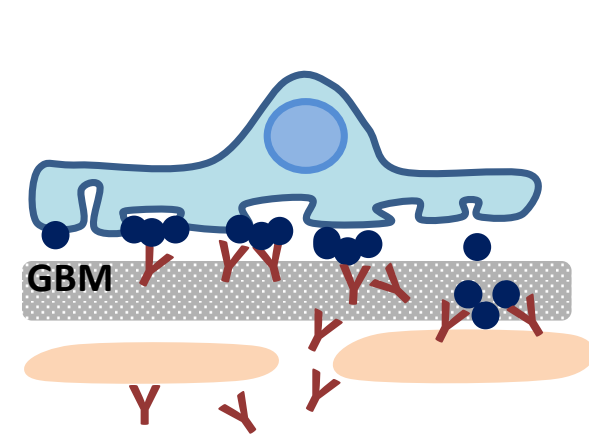

Infant born with MN 
Figure 2

In situ formation of immune deposits and disease progression

Endogenous antigen Exogenous antigen
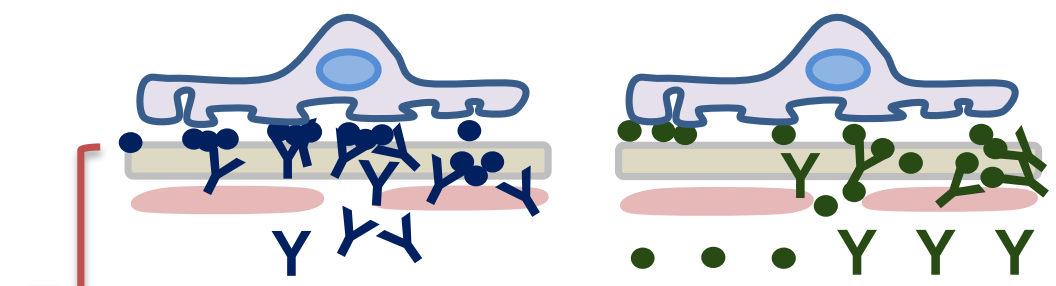

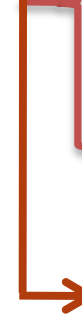
Megalin
PLA2R
NEP
THSD7A

Cationic BSA

ERT enzymes

HepB

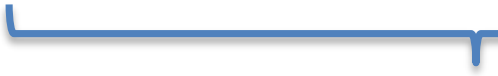

Immune deposits

Direct action of antibodies

$\downarrow$

enzymatic activity receptor function

$\downarrow$

Activation of complement pathways

C5b-9 complex formation insertion into membrane

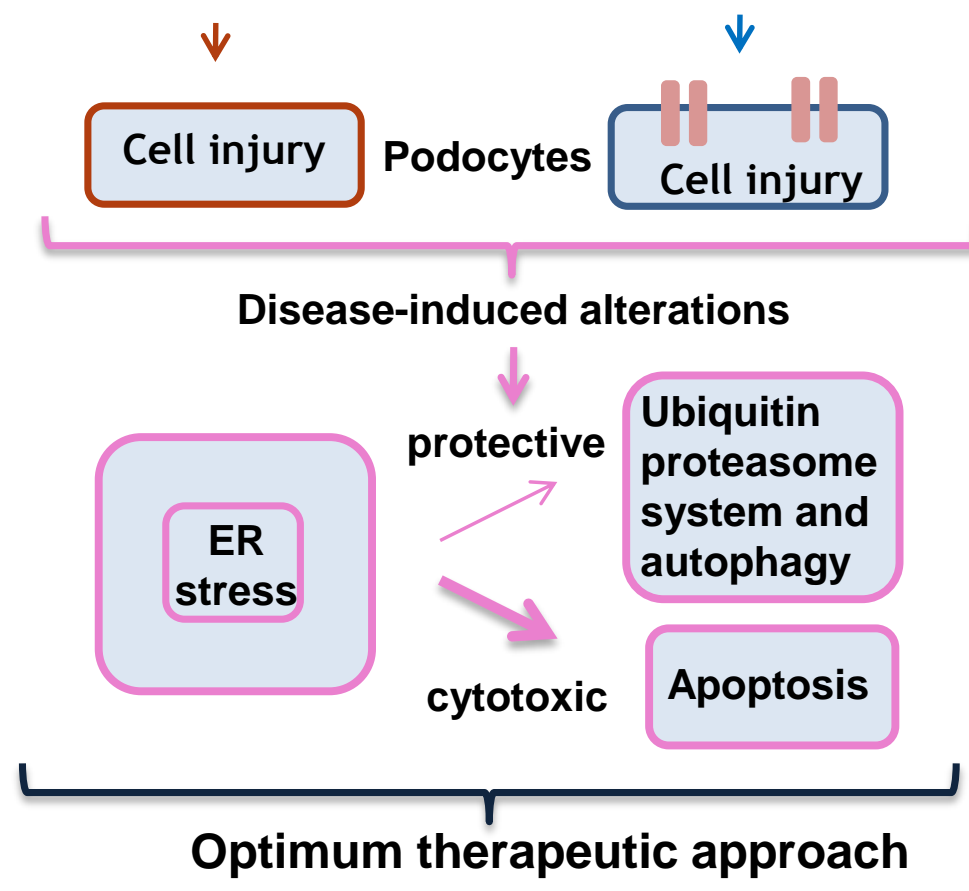

$\begin{array}{cccc}\begin{array}{c}\text { Eliminating } \\ \text { environmental } \\ \text { factors }\end{array} & \begin{array}{c}\text { Reducing } \\ \text { autoantibodies }\end{array} & \begin{array}{c}\text { Inhibiting } \\ \text { complement } \\ \text { activation }\end{array} & \begin{array}{c}\text { Protecting the } \\ \text { podocyte }\end{array} \\ & & & \end{array}$

